\title{
Caracterização química como alternativa de destinação ao uso agrícola do lodo da estação de tratamento de esgoto do Município de Anápolis, Estado de Goiás, Brasil
}

\section{Verediana Fioretin Rosa de Almeida', Renato Rosa de Almeida², Nayane Rosa Gomes², Lucas Rodrigues Caetano², Rafael Choze ${ }^{3}$}

${ }^{1}$ Curso de Engenharia Ambiental e Sanitária. Faculdade Metropolitana de Anápolis (FAMA). Via de Acesso. Av. Fernando Costa, 49. Vila Jaiara Setor Norte. AnápolisGO. Brasil. (CEP 75064-780).

${ }^{2}$ Curso de Engenharia Agrícola. Universidade Estadual de Goiás. Campus de Ciências Exatas e Tecnológicas Henrique Santillo. Via de Acesso. BR-153, 3.105. Caixa Postal 459. Fazenda Barreiro do Meio. Anápolis-GO. Brasil (CEP 75132-903).

${ }^{3}$ Universidade Federal de Goiás. Faculdade Metropolitana de Anápolis (FAMA). Via de Acesso Av. Fernando Costa, 49. Vila Jaiara Setor Norte. Anápolis-GO. Brasil. (CEP 75064-780).

Resumo. A disposição final do lodo de estação de tratamento de esgoto é uma preocupação mundial, em razão do crescente volume produzido. Com o crescimento populacional no Brasil e as melhorias no saneamento básico, aumentou-se consideravelmente o número da população atendida por redes coletoras de esgoto. Diante deste cenário o volume de lodo de esgoto produzido e seu descarte tornaram-se um problema financeiro, ambiental e social devido suas características poluidoras. A disposição destes resíduos no solo pode ser recomendada, pois devido aos teores de matéria orgânica, de macro e micronutrientes podem ser destinados à agricultura, por acrescentar elementos que podem melhorar as características do solo e consequentemente o potencial agrícola das lavouras. Diante desse aspecto, objetivou-se com este trabalho caracterizar o lodo de esgoto produzido pela Estação de Tratamento de Esgoto do Município de Anápolis, Estado de Goiás, Brasil, a partir da avaliação de variáveis químicas, viabilizando a sua possível destinação ao uso agrícola. As amostras de lodo foram coletadas no mês de outubro de 2016 nas lagoas anaeróbica, aerada e de maturação. Após a coleta e o acondicionamento das amostras em embalagens de polipropileno foram encaminhadas ao Laboratório de Solo da Universidade Federal de Goiás (UFG) para serem avaliados os parâmetros de matéria orgânica (MO), nitrogênio $(\mathrm{N})$, fósforo $(\mathrm{P})$, potássio $(\mathrm{K})$, $\mathrm{pH}$ e os macroelementos Zinco $(\mathrm{Zn})$ e Cobre $(\mathrm{Cu})$. Com base nos dados e nas avaliações realizadas, conclui-se que o lodo não deve ser considerado um simples resíduo, pois possui características químicas que lhe conferem o poder de um excelente condicionador do solo, podendo tornar-se um importante aliado na melhoria de práticas agrícolas desenvolvidas no país, além de promover a reciclagem, controle da poluição em aterros sanitários, preservação de recursos naturais e no desenvolvimento sustentável.

Recebido:

$15 / 05 / 2017$

Aceito:

$21 / 06 / 2017$

Publicado:

30/06/2017

Acesso Aberto

Artigo completo

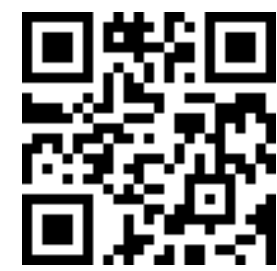

ORCID

(ㄷ) 0000-0002-7354-2252

Verediana Fioretin Rosa de Almeida

(1) 0000-0002-2322-4571

Renato Rosa de Almeida

(1) 0000-0001-5290-4966 Nayane Rosa Gomes (1) 0000-0001-7879-3555 Lucas Rodrigues Caetano

(D) 0000-0003-1721-0031 Rafael Choze 
Palavras-chave: Resíduos; Nutrientes; Disposição final; Reestruturação do solo; Desenvolvimento sustentável.

\begin{abstract}
Chemical characterization as an alternative destination to the agricultural use of sludge from the sewage treatment plant in the Municipality of Anápolis, Goiás State, Brazil. The final disposal of sludge from sewage treatment plants is a global concern because of the increased production of this residue. The number of people served by sewer networks has considerably increased due to population growth and improvements in basic sanitation in Brazil. In this context, the volume of produced sewage sludge and its disposal became a financial, environmental and social problem due to its polluting characteristics. The disposal of this residue in the soil can be recommended since, because of its levels of organic matter and macro- and micronutrients, it can be used in agriculture, providing elements that can improve soil characteristics and, consequently, the potential of crops. Thus, this study aimed to characterize the sewage sludge, produced by a sewage treatment plant in the municipality of Anápolis (Goiás State, Brazil), from the assessment of chemical variables, making viable its possible agricultural use. Sludge samples were collected in October 2016 in anaerobic, aerated and maturation ponds. After collection, the samples were packed in polypropylene packaging and sent to the Laboratory of Soil Analysis of the Federal University of Goiás to be evaluated as the organic matter (OM) nitrogen $(\mathrm{N})$, phosphorus $(\mathrm{P})$, potassium $(\mathrm{K}), \mathrm{pH}$ and the macroelements Zinc (Zn) and copper (Cu). Based on the data analysis, it is concluded that the sludge should not be considered a simple residue since it has chemical characteristics that make it a good soil conditioner, and therefore can be used to improve agricultural practices, in addition to promoting the recycling, pollution control in landfills, preservation of natural resources and sustainable development.
\end{abstract}

Keywords: Waste; Nutrients; Final disposal; Soil restructuring; Sustainable development.

\section{Introdução}

A disposição final do lodo de estação de tratamento de esgoto (ETE) é uma preocupação mundial, em razão do crescente volume produzido, que se não forem manejados de forma adequada, apresentam potencial carga poluidora, gerando sérios problemas socioambientais (Lavezzo, 2016).

Existe hoje uma grande preocupação em relação ao grau de tratamento e ao destino final dos esgotos, a suas consequências sobre o meio ambiente, à qualidade das águas, do ar e do solo (Jordão e Pessoa, 2014). As crescentes exigências da sociedade junto com os órgãos ambientais por melhores padrões de qualidade ambiental têm refletido nos gestores públicos e privados dos serviços de saneamento a buscarem soluções para o destino final do lodo gerado pelas ETE's, devido principalmente aos baixos índices de tratamento ainda verificados (Fernandes et al., 2001).

O reaproveitamento é a melhor solução para o problema dos esgotos, que devem ser tratados para eliminar as impurezas e matar os micro-organismos (Ibrahin et al., 2015). No Brasil, o descarte em sua maioria ainda e realizado em aterros sanitários (Castro et al., 2015), o que intensifica o problema com os resíduos urbanos e vai de encontro à Política 
Nacional de Resíuos Sólidos, que prevê a redução de resíduos sólidos úmidos dispostos em aterros sanitários (Brasil, 2010).

Entre as principais opções e métodos de disposição de lodo das ETE's no meio ambiente, encontram-se $1^{\circ}$ disposição no solo (uso agrícola, florestas, áreas de recuperação), $2^{\circ}$ disposição em aterro, $3^{\circ}$ disposição no mar, e $4^{\circ}$ incineração (Matthews, 1992).

$\mathrm{O}$ método de maior benefício ambiental e econômico é a utilização do lodo nas práticas agrícolas, que além de ser uma solução de longo prazo para a destinação desses resíduos, proporcionam aos solos a elevação do pH, a redução da acidez potencial (Bonini et al., 2015), o aumento da disponibilidade dos nutrientes, de íons trocáveis Soma de Bases (SB), da Capacidade de Troca de Cátions (CTC) e da saturação por bases (V \%) (Romeiro et al., 2014).

A atividade agrícola com ênfase na monocultura tem sido um fator de aceleração da degradação do solo, geralmente ultimada pelo superpastejo e uso do fogo. Nesta fase inicia-se o processo de perda da estrutura do solo e voçorocamento, agravando ainda mais a degradação (Faria e Franco, 1994).

A utilização do lodo de esgoto em solos agrícolas tem como principal beneficio, a incorporação dos macronutrientes nitrogênio $(\mathrm{N})$ e fósforo (P) e micronutrientes como o zinco (Zn), cobre $(\mathrm{Cu})$, ferro $(\mathrm{Fe})$, manganês $(\mathrm{Mn})$ e molibdênio (Mo) (Betiol e Camargo, 2007). No entanto pode se dizer que o lodo de esgoto pode influenciar de forma positiva nas características físicas do solo, como a formação de agregados de partículas do solo, com consequente melhoria da infiltração, da retenção de água e da aeração, com reflexos ambientais imediatos, como a redução da erosão e melhoria da qualidade dos solos degradados (Pedroza et al., 2010).
Sendo assim, esse trabalho tem como objetivo caracterizar o lodo de esgoto produzido pela ETE de Anápolis/GO a partir da avaliação de parâmetros químicos, viabilizando a sua possível destinação ao uso agrícola, reduzindo assim a quantidade de lodo em aterros, além de promover a reciclagem, controle da poluição em aterros sanitários, preservação de recursos naturais e desenvolvimento sustentável.

\section{Materiais e métodos}

\section{Área de estudo}

A Empresa de Saneamento de Anápolis (SANEAGO), no Estado de Goiás, possui um sistema de esgoto sanitário municipal composto por ligações que atendem $60 \%$ da população urbana, capaz de receber uma vazão média de 400 $\mathrm{L} / \mathrm{s}$, operando com oito lagoas de estabilização, sendo, quatro anaeróbias, duas aeradas e duas de maturação (Figura 1), na qual o esgoto tratado é lançado no Córrego das Antas, principal contribuinte na formação da bacia hidrográfica do município. O estudo foi realizado na ETE, situado no Município de Anápolis, que apresenta altitude de $970 \mathrm{~m}$ e coordenadas de referência $48^{\circ}$ 54' 09” de logitude Oeste e $16^{\circ} 17^{\prime} 02^{\prime}$ 'de latitude Sul.

\section{Coleta das amostras}

As amostras foram coletadas em outubro de 2016, em três lagoas, sendo uma anaeróbica, uma aerada e uma de maturação. Efetuou-se a coleta do lodo em cinco pontos das lagoas (Figura 2), coletando $400 \mathrm{~mL}$ de lodo em cada ponto.

Para a coleta do material construiuse um coletor (Figura 4), sendo utilizadas embalagens de polipropileno para o acondicionamento das amostras (Figura 3), após a coleta, as embalagens contendo as amostras foram armazenadas em bolsa térmica e encaminhadas para análise. 


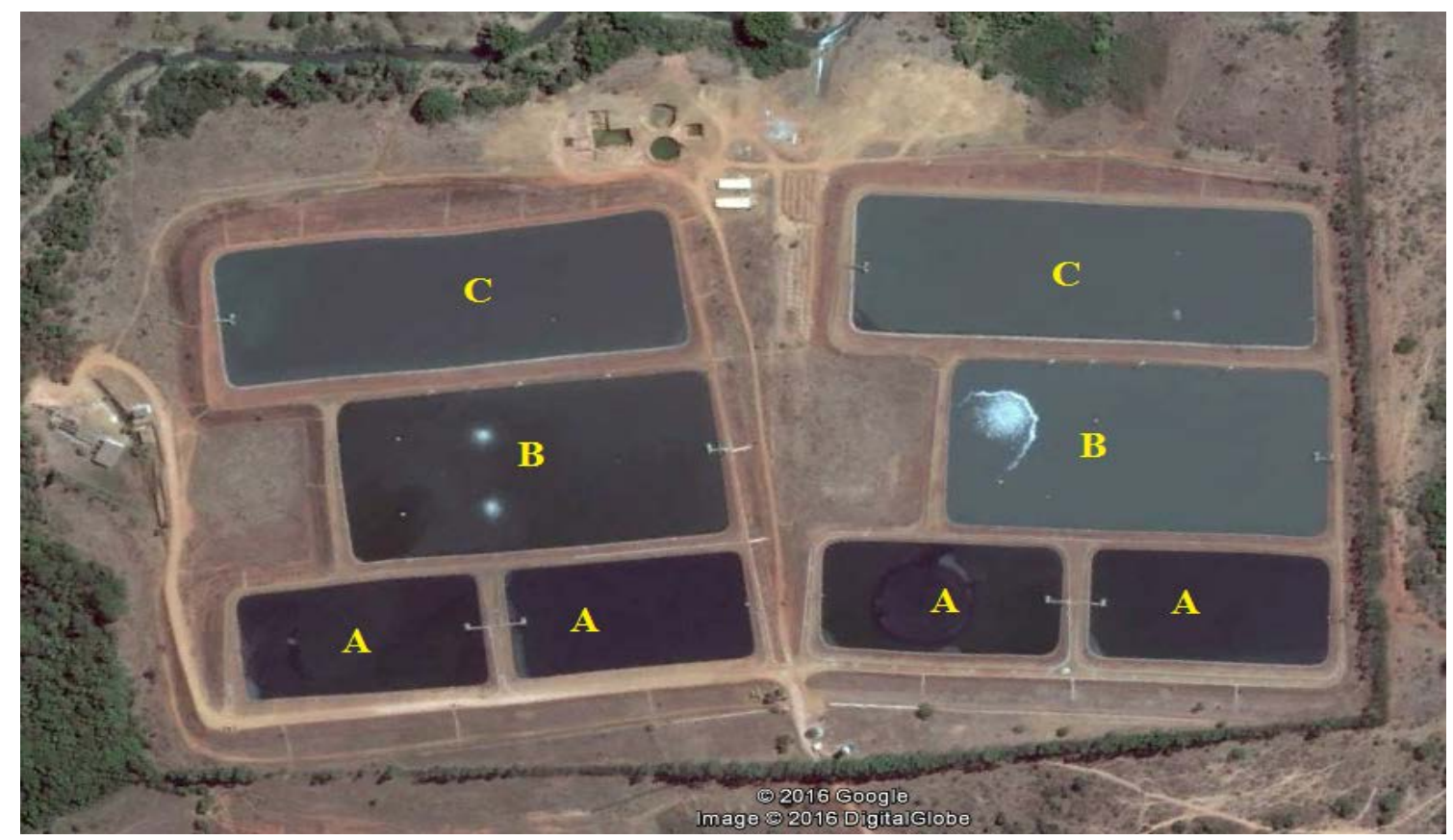

Figura 1. Vista das lagoas anaeróbicas (A), aeradas (B) e maturação (C) da Estação de Tratamento de Esgoto (ETE) de Anápolis-GO. Fonte: Google Earth.

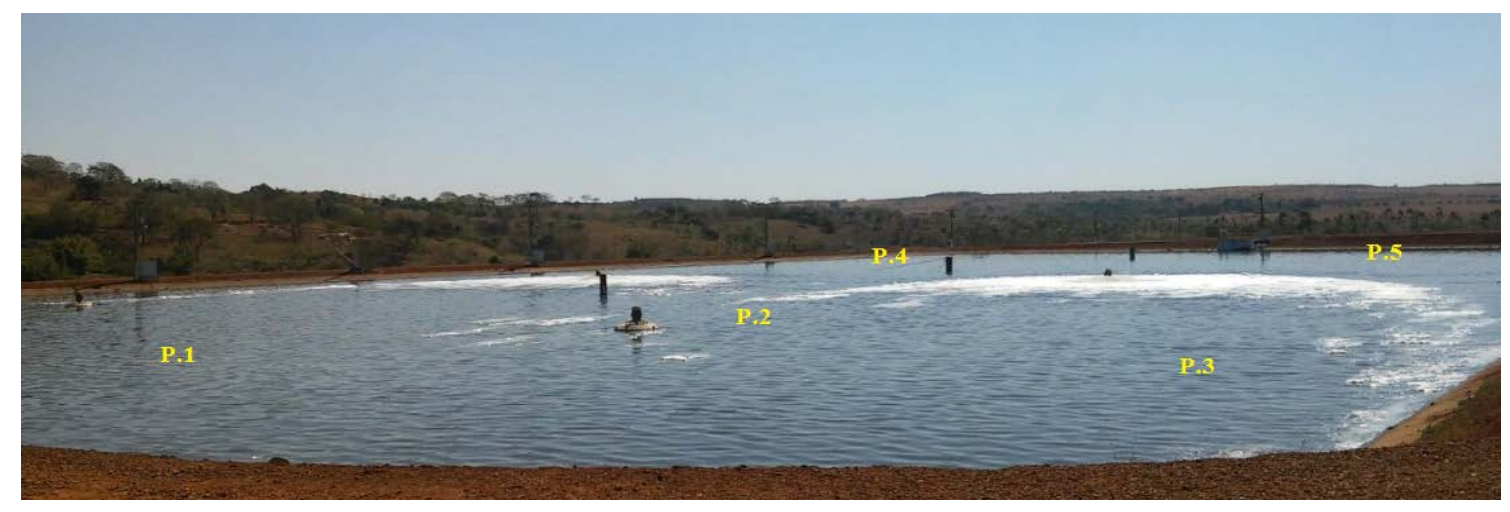

Figura 2. Pontos de coleta do lodo nas lagoas da Estação de Tratamento de Esgoto (ETE) de AnápolisGO.

\section{Concepção do coletor de lodo}

O coletor foi construindo a partir de um cano de PVC de $5 \mathrm{~m}$ com diâmetro de $25 \mathrm{~mm}$ e outro de $4 \mathrm{~m}$ com diâmetro de 32 $\mathrm{mm}$, em seguida realizou-se um furo no centro de uma borracha recortada a partir da medida do cano de $32 \mathrm{~mm}$ e $14 \mathrm{~mm}$ de espessura, utilizando um parafuso de $3 \mathrm{~mm}$ de diâmetro e comprimento de $5 \mathrm{~cm}$, seguindo colocou-se uma arruela na haste do parafuso, fixando-o no centro da borracha seguida de outra arruela presa com uma porca.
Em seguida fez-se o êmbolo com o pedaço de cabo de vassoura de $1 \mathrm{~cm}$ de comprimento e diâmetro de $25 \mathrm{~mm}$, fixando-a em uma das extremidades do cano de $25 \mathrm{~mm}$. Posteriormente, fixou-se o parafuso de $3 \mathrm{~mm}$ de diâmetro, deixando 1 $\mathrm{cm}$ entre o pedaço de madeira e a parte com a borracha. Na outra extremidade do cano de $25 \mathrm{~mm}$ colou-se um T de PVC. No final, o cano de $25 \mathrm{~mm}$ foi colocado dentro do cano de $32 \mathrm{~mm}$, efetuando-se assim a pressão para que fosse possível sugar o lodo. 


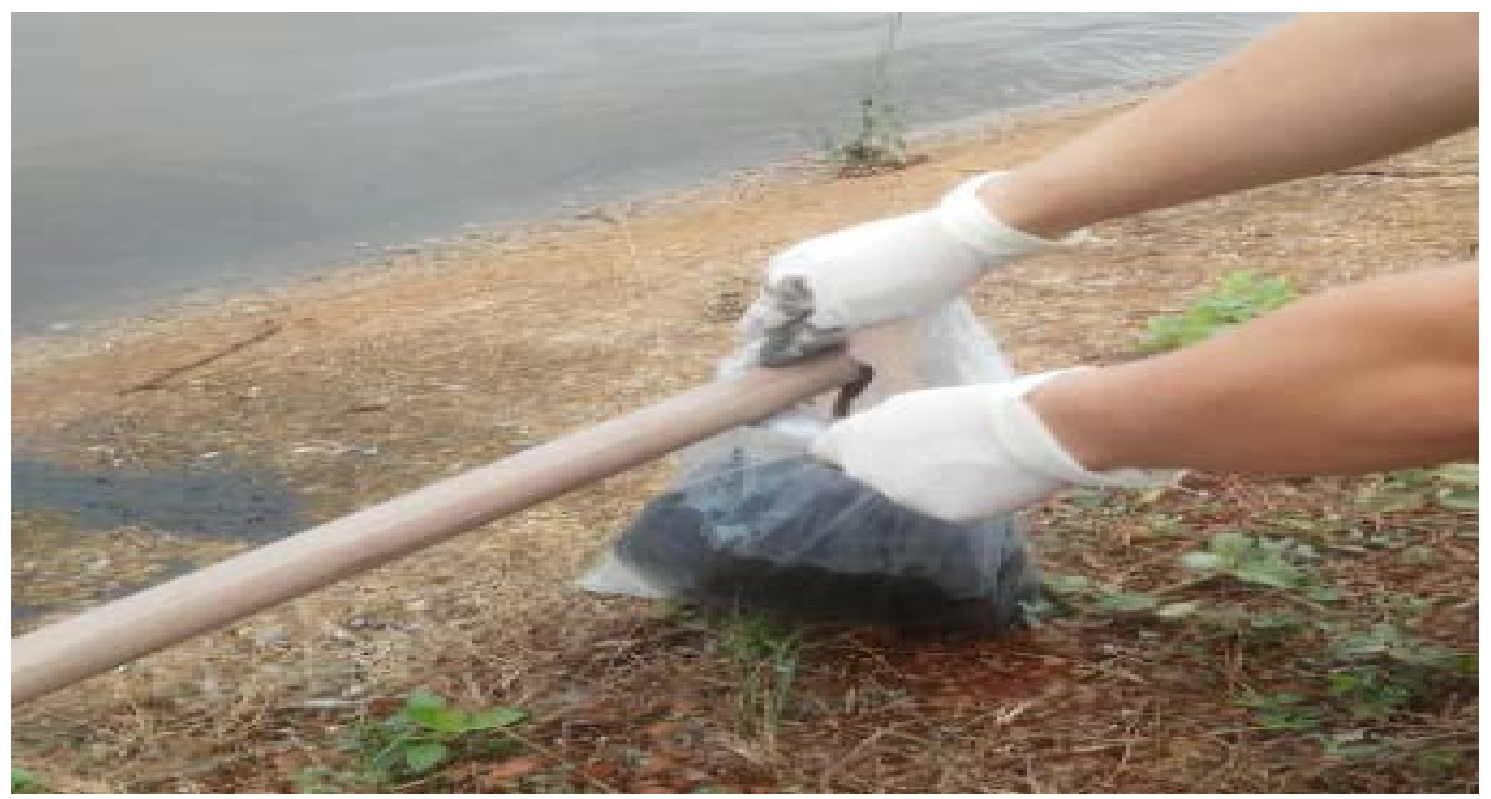

Figura 3. Coleta do lodo e armazenamento das amostras em sacos de polipropileno.

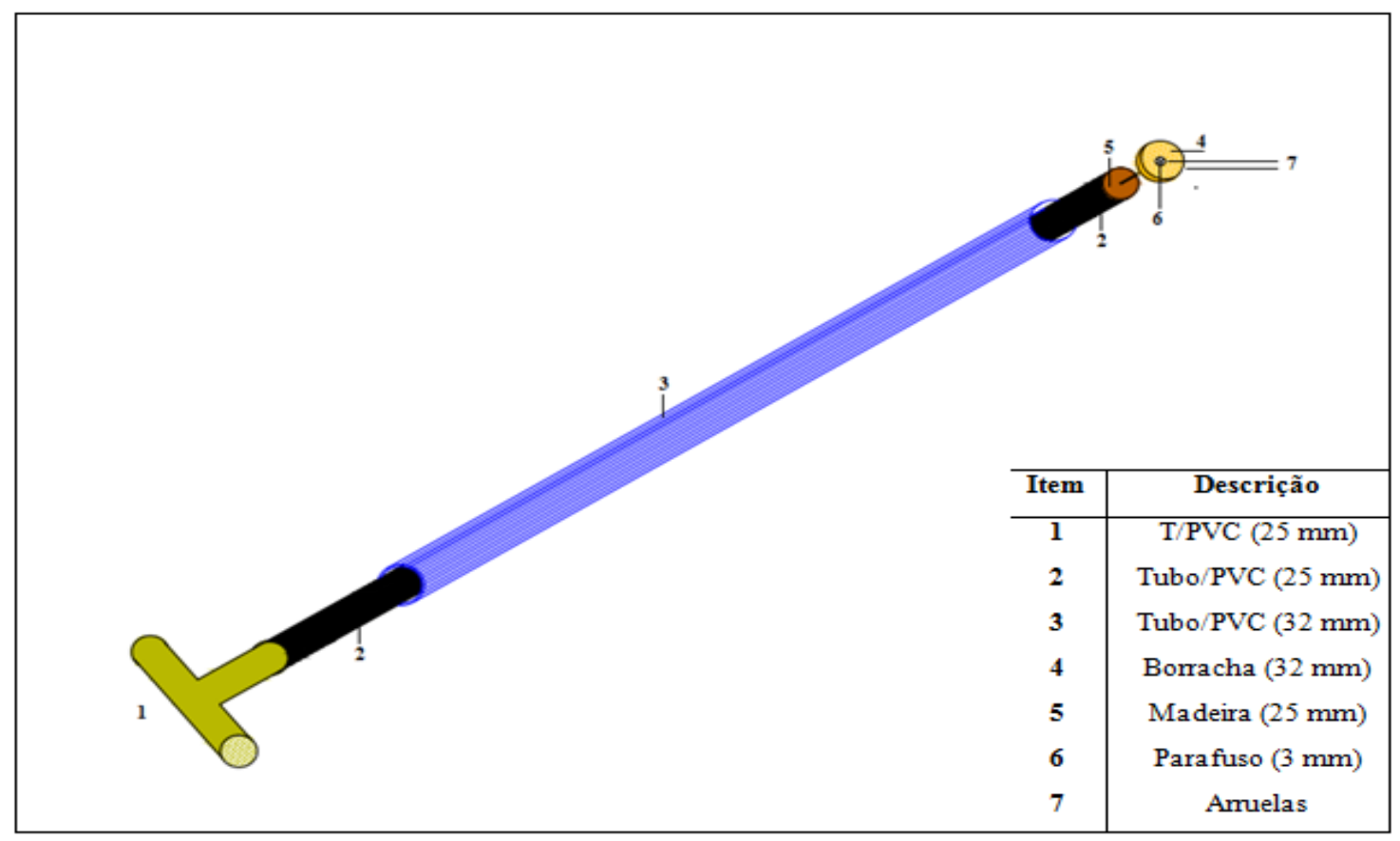

Figura 4. Partes constituintes e materiais utilizados na construção do coletor de lodo.

\section{Realização das análises}

Após a coleta, direcionou as amostras ao Laboratório de Solos da Universidade Federal de Goiás (UFG) para análises de matéria orgânica, nitrogênio, fósforo, potássio, pH, cobre e zinco. Os dados obtidos com as análises foram inseridos no Excel $^{\circledR}$ para confecção dos gráficos. 


\section{Resultados e discussão}

\section{Matéria orgânica}

A matéria orgânica quando presente no solo melhora a resistência, erosão e ao adensamento, ativando assim a vida microbiana, além de aumentar a resistência das plantas a pragas e doenças (Sanepar e Prosab, 1999).

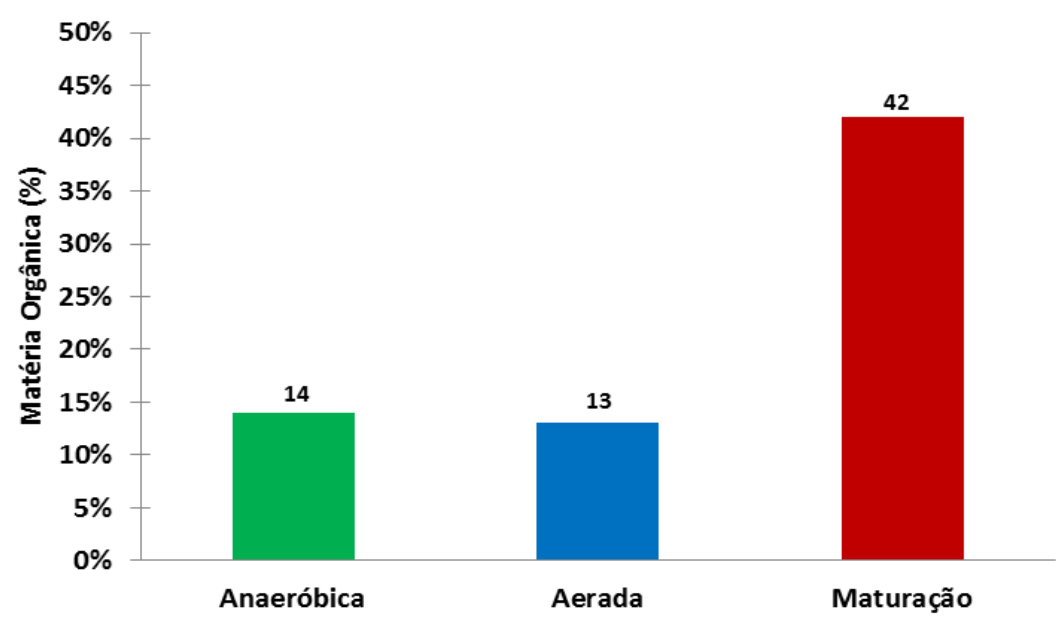

Figura 5. Teor de Matéria Orgânica em (\%) presente nas amostras de lodo das lagoas anaeróbica, aerada e maturação da ETE de Anápolis/GO.

Os resultados obtidos com as amostras de lodo das lagoas anaeróbicas e aerada da ETE apresentaram uma pequena variação de matéria orgânica. O maior teor de matéria orgânica registrado foi evidenciado na lagoa de maturação com $42 \%$, e o menor valor encontrado para o experimento foi para a lagoa aerada com 13\% (Figura 5).

Freddo (2014) ao estudar a ETE de Santa Helena/PR, encontrou o maior teor de matéria orgânica registrado para o mês de março na lagoa anaeróbica, sendo 39,22\%, de modo que o menor valor encontrado foi verificado na lagoa facultativa no mês de março, ou seja, $18,64 \%$ de matéria orgânica. Também contrario ao resultado desse experimento, Sanepar e Prosab (1999) ao trabalha com lodo anaeróbico da ETE de Curitiba/PR, encontrou valor de 36,2\% para matéria orgânica.

\section{pH}

$\mathrm{O} \mathrm{pH}$ pode ser considerado um bom indicador do estado de decomposição da matéria orgânica. Devido ao seu aumento, a atividade microbiana é favorecida aumentando assim a mineralização da matéria orgânica e consequentemente o aumento da disponibilidade de micronutrientes (Kiehl, 1985; Correia, 2009).

Observou-se que as amostras de lodo da ETE (Figura 6) indicaram uma pequena variação de $\mathrm{pH}$ entre as lagoas, sendo que o maior valor observado para a lagoa de maturação de 6,7 e o menor valor na lagoa anaeróbica de 6,5.

Os valores encontrados se aproximam dos encontrados na ETE do município de Jerônimo Monteiro (sistema australiano) que indicaram $\mathrm{pH}=6,3$ (Lopes et al., 2005), valores semelhantes para esse fator foi observado também por Maria et al. (2010), onde foi encontrado $\mathrm{pH}$ de 6,3 para lodo de esgoto aplicado em solo agrícola.

Korentajer (1991) relata que o transporte dos elementos tóxicos quando o lodo de esgoto é adicionado ao solo é mínimo quando o $\mathrm{pH}$ do é mantido em 
valor igual ou superior a 6,5. Isso mostra que o $\mathrm{pH}$ das amostras de lodo da ETE de Anápolis/GO possui condições favoráveis para a atividade microbiana e decomposição de material orgânico.

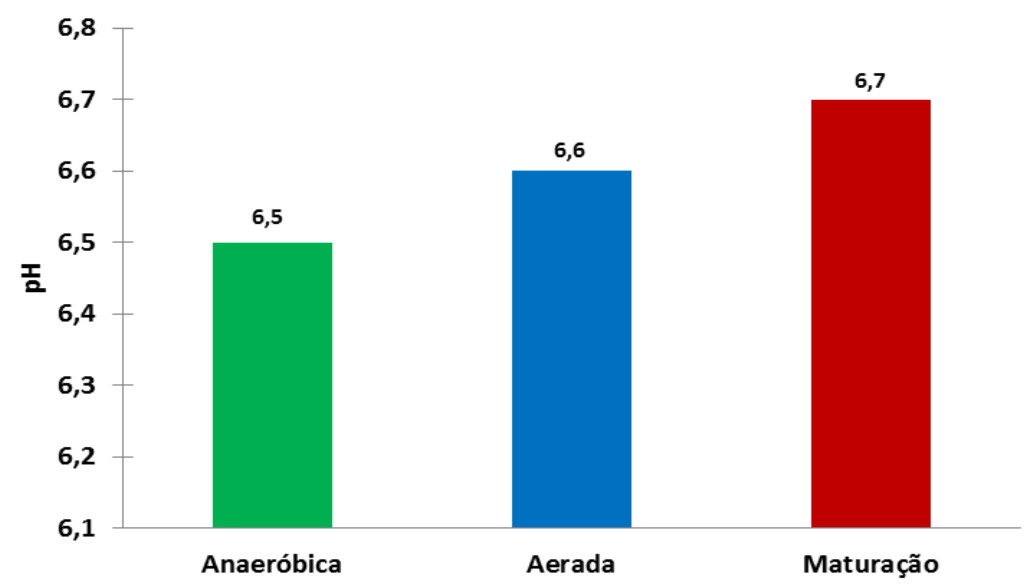

Figura 6. pH das amostras de lodo das lagoas anaeróbica, aerada e maturação da ETE de Anápolis/GO.

\author{
Nitrogênio, fósforo e potássio \\ $\mathrm{O}$ nitrogênio $(\mathrm{N})$, fósforo $(\mathrm{P})$ e \\ potássio (K) são chamados de \\ macroelementos, pois são utilizados em
}

grande quantidade pelas plantas, sendo fundamental em todas as etapas de seu ciclo, sendo ela crescimento, florescimento e frutificação.

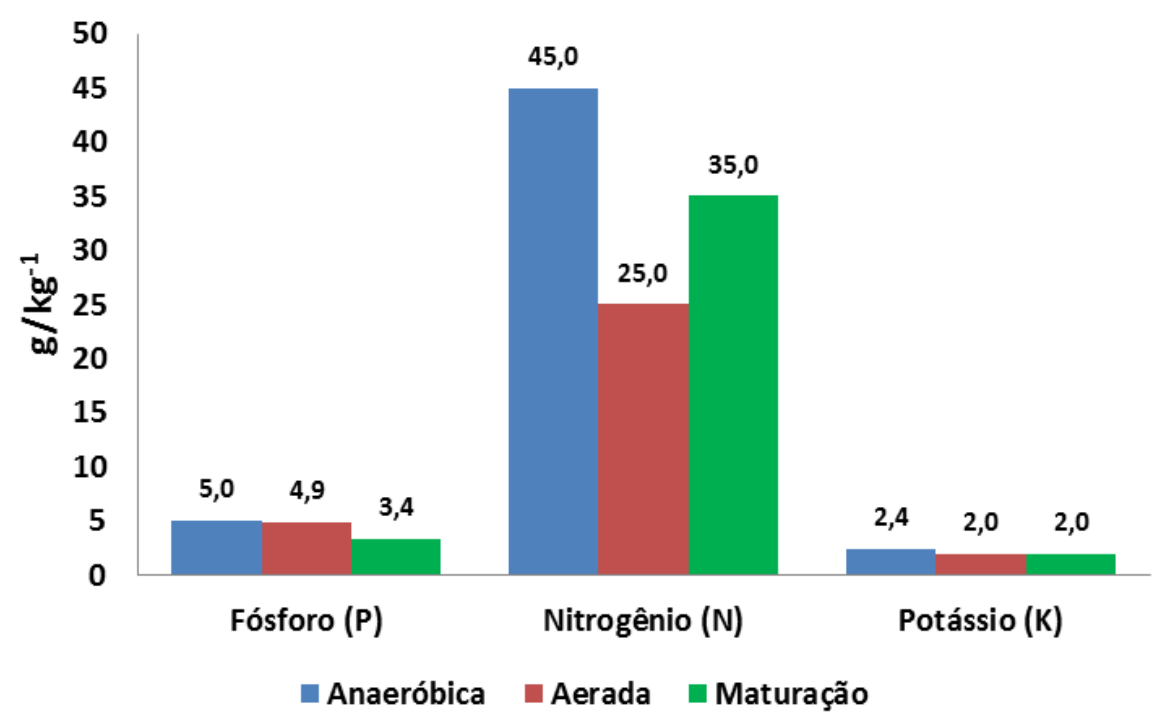

Figura 7. Teor de nitrogênio $(\mathrm{N})$, fósforo $(\mathrm{P})$ e potássio $(\mathrm{K})\left(\mathrm{g} / \mathrm{kg}^{-1}\right)$ presentes nas amostras de lodo das lagoas anaeróbica, aerada e maturação da ETE de Anápolis/GO. 
Nitrogênio: a deficiência de nitrogênio nas plantas ocasiona um crescimento retardado e lento, fazendo com que não tenham uma aparência luxuriante (Epstein e Bloom, 2006). As a amostra analisadas junto a ETE (Figura 7) apresentaram uma maior concentração de nitrogênio para a lagoa anaeróbia, $45 \mathrm{~g} / \mathrm{kg}^{-1}$ e menor para à lagoa aerada $25 \mathrm{~g} / \mathrm{kg}^{-1}$.

O resultado das amostras indicam um resultado satisfatório comparado com os citados por Coelho et al. (2011) que encontraram uma concentração de $31,8 \mathrm{~g} / \mathrm{kg}^{-1}$ de nitrogênio no lodo proveniente da ETE da cidade de Jundiaí/SP, analisado para aplicações na cultura de bananeira. Conforme Santos (2005) a composição média do lodo gerado nas ETE's no Brasil contém 10,7 g/ $\mathrm{kg}^{-1}$ de nitrogênio. Diante desse aspecto pode se dizer que a ETE de Anápolis está bem a cima da média, com um grande potencial para a agricultura.

Fósforo: os primeiros sintomas de deficiência de fósforo ocorrem com o desenvolvendo de pigmentos vermelhos, purpúreos e marrons nas folhas, especialmente ao longo das nervuras, onde o crescimento é reduzido, e com grandes níveis de deficiência as plantas tornam-se raquíticas (Epstein e Bloom, 2006).

Os resultados encontrados para fósforo na ETE (Figura 7) demonstraram maior concentração desse elemento no lodo proveniente da lagoa anaeróbica, com uma concentração de $5,0 \mathrm{~g} / \mathrm{kg}^{-1}$ e menor concentração na lagoa de maturação de $3,4 \mathrm{~g} / \mathrm{kg}^{-1}$.

Barbosa (2016) cita em seu trabalho a aplicação de lodo em latossolo vermelho e na cultura de milho, na qual encontrou valores de concentração de fósforo no lodo de $6,55 \mathrm{~g} / \mathrm{kg}^{-1}$. Pereira (2015) obteve uma média de $7,80 \mathrm{~g} / \mathrm{kg}^{-1}$ de fósforo ao analisar o lodo proveniente de uma estação de tratamento de efluentes de uma indústria alimentícia.

Comparando os resultados encontrados de fósforo para as lagoas da ETE de Anápolis, a lagoa anaeróbica foi a que mais se aproximou dos autores mencionado. Estando de acordo com
Resolução CONAMA n ${ }^{0}$ 375/2006, "potencial agronômico do lodo" que é necessário ao desenvolvimento das plantas (Brasil, 2006).

Potássio: o potássio interage com quase todos os nutrientes essenciais à planta, diferente dos demais nutrientes, este elemento não forma compostos nas plantas, mas permanece livre para regular muitos processos essenciais para o desenvolvimento da cultura (Unifertil, 2012).

A lagoa que apresentou maior concentração de potássio no decorrer das análises foi à anaeróbica $2,4 \mathrm{~g} / \mathrm{kg}^{-1}$ e com menores valores as lagoas aeradas e de maturação, sendo encontradas as concentrações iguais de 2,0 g/ $\mathrm{kg}^{-1}$ (Figura 7).

Os valores de potássio encontrados para as amostras da ETE de Anápolis apresentaram concentrações próximas as citadas por Costa et al. (2014), que encontraram 2,8 g/ $\mathrm{kg}^{-1}$ desse elemento como adubação mineral. Valores superiores foram observados por Pereira (2015), obtendo uma média de $6,85 \mathrm{~g} / \mathrm{kg}^{-1}$ de potássio ao analisar o lodo proveniente de uma estação de tratamento de efluentes de uma indústria alimentícia.

\section{Cobre e zinco}

As plantas absorvem pequenas quantidades destes metais, quando ocorre à aplicação por muitos anos em altas doses pode levar a ao acumulo no solo, além de causar efeito de toxicidade às plantas (Mattias et al., 2010). Segundo Zampieri (2010) a falta ou excesso deste micronutriente desencadeia fenômenos fisiológicos os quais podem ser externados pelas plantas com sintomas visíveis na morfologia, anatomia e na interdependência com outros metais necessários para o desenvolvimento e crescimento das plantas.

Os principais sintomas ocasionados pelo excesso de cobre e visualizado no sistema radicular das plantas, pois perdem rapidamente o seu vigor e escurecem, apresentam também engrossamento e paralisam o crescimento. $\mathrm{O}$ zinco $\mathrm{e}$ considerado como um ativador enzimático nas plantas e controla a produção de 
importantes reguladores de crescimento, em excesso a planta podem apresentar folhas com pigmentação vermelha no pecíolo e nas nervuras (Yruela, 2005; Kumar et al., 2008; Hänsch e Mendel, 2009).

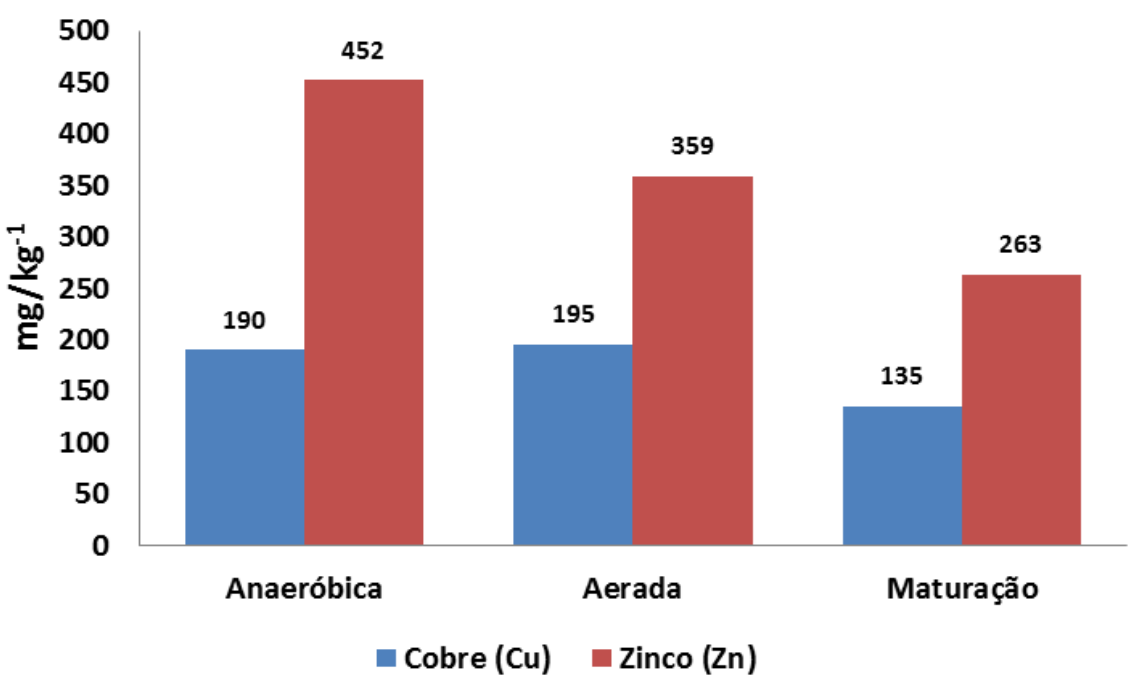

Figura 8. Teor de Cobre e Zinco (mg/ $\mathrm{kg}^{-1}$ ) presente nas amostras de lodo das lagoas anaeróbica, aerada e maturação da ETE de Anápolis/GO.

Cobre: a maior concentração de cobre foi observada na lagoa aerada com $195 \mathrm{mg} / \mathrm{kg}^{-1}$, e menor concentração para a lagoa de maturação, 135 mg/ $\mathrm{kg}^{-1}$ (Figura 8). Valores superiores ao desse experimento foi verificado por Benzan (2010), que encontrou $584,9 \mathrm{mg} / \mathrm{kg}^{-1}$, sendo avaliado o lodo da ETE de Monjolinho Município de São Carlos/SP. Costa et al. (2014), também observou valores elevados de $562 \mathrm{mg} / \mathrm{kg}^{-1}$ para este fator se comparada com esse estudos, na qual foi analisado lodo da ETE de Jundiaí/SP.

Considerando $195 \mathrm{mg} / \mathrm{kg}^{-1}$ baixa para esse estudo, o lodo da ETE de Anápolis pode ser utilizado em solos sem perigo de contaminação por cobre conforme a Resolução CONAMA n ${ }^{\circ}$ 375/2006, onde os valores máximos de concentrações de cobre estipulados são de até $1.500 \mathrm{mg} / \mathrm{kg}^{-1}$ (Brasil, 2006),

Zinco: para esse fator a lagoa que apresentou maior concentração foi a lagoa anaeróbica com $452 \mathrm{mg} / \mathrm{kg}^{-1}$ e a com menor valor da concentração de zinco foi a da lagoa de maturação, com $263 \mathrm{mg} / \mathrm{kg}^{-1}$ (Figura 8). Conforme a resolução CONAMA $n^{\circ}$ 375/2006 a concentração máxima permitida no lodo de esgoto ou produto derivado de zinco é $2800 \mathrm{mg} / \mathrm{kg}^{-1}$ (Brasil, 2006).

Os resultados encontrados por Costa et al. (2001) foram de $584 \mathrm{mg} / \mathrm{kg}^{-1}$ em lodo sem higienização coletado na lagoa anaeróbia na ETE da Serra/ES, em análise química do lodo no cultivo do mamoeiro. Benzan (2010), ao estudar os componentes químicos do lodo da ETE de Monjolinho Município de São Carlos/SP, obteve $1.549,0 \mathrm{mg} / \mathrm{kg}^{-1}$ para o zinco, valor relativamente auto se comparado com o desse experimento.

\section{Conclusão}

Percebe-se que a quantidade de lodo gerado nas ETE's tende a aumentar a cada dia mais devido a fatores como o crescimento populacional. Diante desse aspecto faz se necessário à criação e desenvolvimento de técnica para a 
destinação segura desse resíduo, reduzindo assim pressão sobre o meio ambiente além de gerar mais sustentabilidade a sociedade.

$$
\text { Considerando os dados }
$$

apresentadas pode-se observar que o lodo da ETE de Anápolis/GO apresenta consideráveis concentrações de nutrientes essenciais para o desenvolvimento de planta e carga de metal pesado dentro dos limites estabelecidos pela Resolução CONAMA $n^{\circ}$ 375/2006 para utilização no solo.

Dessa forma pode-se concluir que o lodo não deve ser considerado um simples resíduo, a aplicação deste material na agricultura é totalmente viável, podendo tornar-se um importante aliado na melhoria de práticas agrícolas desenvolvidas no país, além de contribuir para minimizar os impactos ambientais causados por este resíduo.

\section{Declaração de conflitos de interesse}

Os autores declaram não haver conflito de interesse.

\section{Referências}

Barbosa, R. S. Efeito do lodo de esgoto em latossolo vermelho e na cultura de milho. Alfenas: Universidade Federal de Alfenas, 2016. (Dissertação de mestrado).

Benzan, R. Validação de metodologia analítica para determinação de cromo e zinco em biossólido. São Carlos: Universidade Federal de São Carlos, 2010. (Dissertação de mestrado).

Betiol, W; Camargo, O. A. Lodo de esgoto na agricultura: potencial de uso e problemas. Belo Horizonte: TEC hoje Belo Horizonte, 2007.

Bonini, C. S. B.; Alves, M. C.; Montanari, R. Lodo de esgoto e adubação mineral na recuperação de atributos químicos de solo degradado. Revista Brasileira de Engenharia Agrícola e Ambiental, v. 19, n. 4, p. 388-393, $2015 . \quad$ http://dx.doi.org/10.1590/18071929/agriambi.v19n4p388-393

Brasil. Lei $\mathbf{n}^{\mathbf{0}}$ 12.305, de 2 de agosto de 2010. Institui a Política Nacional de Resíduos Sólidos; altera a Lei $\mathrm{n}^{\circ}$ 9.605, de 12 de fevereiro de 1998; e dá outras providências. Disponível em: <http://www.planalto.gov.br/ccivil_03/_ato2007 -2010/2010/lei/l12305.htm>. Acesso em: 26 abr. 2017.
Brasil. Resolução CONAMA no ${ }^{375}$, de 29 de agosto de 2006. Define critérios e procedimentos, para o uso agrícola de lodos de esgoto gerados em estações de tratamento de esgoto sanitário e seus produtos derivados, e dá outras providências. Disponível em: <http://www.mma.gov.br/port/conama/res/res06 /res37506.pdf> . Acesso em: 26 abr. 2017.

Castro, A. L. F. G.; Silva, O. R.; Scalize, P. S. Cenário da disposição do lodo de esgoto: uma revisão das publicações ocorridas no Brasil de 2004 a 2014. Multi-Science Journal, v. 1, n. 2, p. 66-73, $2015 . \quad$ Disponível em: $<$ https://www.ifgoiano.edu.br/periodicos/index. php/multiscience/article/view/84/48>. Acesso em: 26 abr. 2017.

Coelho, H. A.; Grassi Filho, H.; Romeiro, J. C. T.; Pompermayer, G. V.; Barbosa, R. D.; Lobo, T. F. Desempenho agronômico do lodo de esgoto como fonte de nitrogênio em bananeiras. Revista Agrarian., v. 4, n. 13, p. 172-181, 2011. Disponível em: <https://repositorio.unesp.br/handle/11449/1376 39>. Acesso em: 26 abr. 2017.

Correia, J. E. Caracterização físico-química e microbiológica do lodo gerado na Estação de Tratamento de Esgoto Contorno. Feira de Santana: Universidade Estadual de Feira de Santana, 2009. (Dissertação de mestrado).

Costa, V. L.; Maria, I. C.; Camargo, O. A.; Grego, C. R.; Melo, L. C. A. Distribuição espacial de fósforo em latossolo tratado com lodo de esgoto e adubação mineral. Revista Brasileira de Engenharia Agrícola e Ambiental, v. 18, n. 3, p. 287-293, 2014. http://dx.doi.org/10.1590/S141543662014000300007

Costa, A. N.; Costa, A. F. S.; Silva, A. L. B.; Andrade, M. C. F. E.; Andrade, B. F. E.; Gonçalves, R. F. Utilização agrícola do lodo de ETE anaeróbia como fonte de matéria orgânica e nutrientes no mamoeiro. In: $21^{\circ}$ Congresso brasileiro de Engenharia Sanitária e Ambiental, 2001, João Pessoa. Anais... São Leopoldo: Centro de Ciências Exatas e Tecnológicas da Unisinos, 2001. p. 5.

Epstein, E.; Bloom, A. J. Nutrição mineral de plantas: princípios e perspectivas. Londrina: Planta, 2006.

Faria, S. M.; Franco, A. A. Espécies de leguminosas fixadoras de nitrogênio para revegetação de áreas degradadas. In: Simpósio Sul-Americano, 1, Simpósio nacionalrecuperação de áreas degradadas, 2, 1994, Foz do Iguaçu. Anais... Curitiba: Fundação de 
Pesquisas Florestais do Paraná, 1994. p. 499-508.

Fernandes, F.; Lopes, D. D.; Andreoli, C. V.; Silva, S. M. C. P. Avaliação de alternativas e gerenciamento do lodo na ETE. In: Andreoli, C. V.; Sperling, M. V.; Fernandes, F. Princípios do tratamento biológico de águas residuárias. 1. ed. Belo Horizonte: DESA /UFMG, 2001. p. 299-317.

Freddo, A. Caracterização físico-química de lodo proveniente de duas estações de tratamento de esgoto da Região Oeste do Paraná. Paraná: Universidade Tecnológica Federal do Paraná, 2014. (Monografia de graduação).

Hänsch, R.; Mendel, R. R. Physiological functions of mineral micronutrients $(\mathrm{Cu}, \mathrm{Zn}$, $\mathrm{Mn}, \mathrm{Fe}, \mathrm{Ni}, \mathrm{Mo}, \mathrm{B}, \mathrm{Cl})$. Current Opinion in Plant Biology, v. 12, n. 3, p. 259-266, 2009. https://doi.org/10.1016/j.pbi.2009.05.006

Ibrahin, F. I. D.; Ibrahin, F. J.; Cantuária, E. R. Análise ambiental. 6. ed. São Paulo: Érica, 2015.

Jordão, E. P.; Pessoa, C. A. Tratamento de esgotos domésticos. 7. ed. Rio de Janeiro: ABES, 2014.

Kiehl, E. J. Fertilizantes orgânicos. Piracicaba: Agronômica Ceres, 1985.

Korentajer, L. A review of the agricultural use of sewage sludge: benefits and potential hazards. Walter S.A., v. 17, n. 3, p. 189-196, 1991.

Kumar, P.; Tewari, R. K.; Sharma, P. N. Cadmium enhances generation of hydrogen peroxide and amplifies activities of catalase, peroxidases and superoxide dismutase in maize. Journal of Agronomy and Crop Science, $\begin{array}{llll}\text { v. } 194, & \text { n. } 1, & \text { p. } 72-80, & \end{array}$ http://dx.doi.org/10.1111/j.1439-

037X.2007.00285.X

Lavezzo, L. F. Atributos químicos, bioquímicos e microbiológicos em solos com 18 anos de aplicações anuais de lodo de esgoto. Jaboticabal: Universidade Estadual Paulista, 2016. (Dissertação de mestrado).

Lopes, J. C.; Ribeiro, L. G.; Araújo, M. G.; Beraldo, M. R. B. S. Produção de alface com doses de lodo de esgoto. Horticultura Brasileira, v. 23, n. 1, p. 143-147, 2005. http://dx.doi.org/10.1590/S010205362005000100030
Maria, I. C.; Chiba, M. K.; Costa, A.; Berton, R. S. Sewage sludge application to agricultural land as soil physical conditioner. Revista Brasileira de Ciência do Solo, v. 34, n. 3, p. 967-974, 2010. http://dx.doi.org/10.1590/S010006832010000300038

Mattias, J. L.; Ceretta, C. A.; Nesi, C. N.; Girotto, E.; Trentin, E. E.; Lourenzi, C. R.; Vieira, R. C. B. Copper, zinc and manganese in soils of two watersheds in Santa Catarina with intensive use of pig slurry. Revista Brasileira de Ciência do Solo, v. 34, n. 4, p. 1445-1454, $2010 . \quad$ http://dx.doi.org/10.1590/S010006832010000400040

Matthews, P. J. Sewage sludge disposal in the UK: a new challenge for the next twenty years. Journal of the Institution of Water Environmental Management, v. 6, p. 551-559, 1992. http://dx.doi.org/10.1111/j.17476593.1992.tb00790.x

Pedroza, M. M.; Vieira, G. E. G.; Sousa, J. F.; Pickler, A. C.; Leal, E. R. M.; Milhomen, C. C. Produção e tratamento de lodo de esgoto: uma revisão. Revista Liberato, v. 11, n. 16, p. 89-188, 2010.

Pereira, A. C. A. Efeitos da disposição de lodo de ETE de indústria alimentícia no solo: estudo de caso. Rio Claro: Universidade Estadual Paulista "Júlio de Mesquita Filho", 2015. (Dissertação de mestrado).

Romeiro, J. C. T.; Grassi Filho, H.; Moreira, L. L. Q. Absorção de N, P, K, Ca e Mg por laranjeiras 'pêra' fertilizadas com lodo de esgoto compostado em substituição à adubação nitrogenada mineral. Irriga, v. 19, n. 1, p. 82-93, 2014. https://dx.doi.org/10.15809/irriga.2014v19n1p82

Sanepar; Prosab. Uso e manejo do lodo de esgoto na agricultura. Curitiba: Sanepar; Prosab, 1999.

Santos, E. R. Caracterização química, microbiológica e toxidade do lodo de esgoto da Estação de Mangueira, Pernambuco, Brasil. Recife: Universidade Católica de Pernambuco, 2005. (Pós-Graduação em Desenvolvimento em Processos Ambientais).

Unifertil - Universal de Fertilizantes. Nutrientes do que as plantas precisam. 2012, 002/Ano 02. Disponível em: <http://www.unifertil.com.br/ admin/files/rc20121011151121.pdf $>$. Acesso em: 25 abr. 2016. 
Yruela, I. Copper in plants. Braz. J. Plant Physiol., v. 17, $\quad$ n. 1, p. 145-156, 2005. http://dx.doi.org/10.1590/S1677-

04202005000100012

Zampieri, M. C. T. Estudo sobre os efeitos do cobre e zinco no crescimento da plântula de Aechmea blanchetiana (Baker) L. B. Smith cultivada in vitro. Aplicação da análise por ativação com nêutrons. São Paulo: Instituto de Pesquisas Energéticas e Nucleares, 2010. (Dissertação de mestrado).

Informação da Licença: Este é um artigo Open Access distribuído sob os termos da Licença Creative Commons Attribution, que permite uso irrestrito, distribuição e reprodução em qualquer meio, desde que a obra original seja devidamente citada. 